The results seem to have confirmed those obtained by Luna 9 . The level of radioactivity on the Moon's surface is low, and measurement of the cosmic ray reflectance of the surface shows that the Moon reflects 25 per cent of the particles which fall on to it from space. Photography showed once again that there is no layer of dust on the Moon's surface, which is covered with small stones a few centimetres in diameter. The Russian results suggest that these stones had fallen quite slowly onto the lunar surface and were certainly not meteorites, which would have given cratering.

In addition, Luna 13 carried out measurements of the physical properties of the surface. Rods were driven into the ground by an explosive device to a depth of $20-30 \mathrm{~cm}$, and the density was measured by a beam of gamma radiation distributed along the surface. These measurements show that the surface of the Moon has mechanical properties similar to the properties of terrestrial soil of medium density. The density of the surface is much less than that of the Earth, and much less than the average density of the Moon.

\section{Economic Geochemistry}

GEOCHEMISTRY is still struggling for a place in the hierarchy of recognized sciences. After the Second World War the subject promised to be an important tool for economic geologists, but this promise has not been fulfilled and the techniques of geochemistry have so far been principally used for such tasks as tracing the movement of underground water and prospecting for uranium. The investigation using geochemical methods of the Pequop Mountains area in Elko County, Nevada, by the U.S. Geological Survey is therefore welcome (U.S. Geol. Survey Bull., 1198-E, 1966). The area had no previous history of metal production but possessed a host rock type (dolomite) and a structure favourable to the formation of ores. Conventional sampling and analysis of stream sediments failed to reveal anomalously high concentrations of metals, but analysis of river cobbles and pebbles showed contents of more than 1 per cent of lead and zinc, with lesser amounts of mercury, antimony and arsenic. The metals were concentrated in iron rich fracture fillings or gossan pods (with or without barite), both of which were associated with silicified limestone. Only detailed mapping will reveal whether these metals are present in commercially exploitable amounts.

\section{Crater in the Lake}

A SweDrSir geologist has suggested that a submerged circular depression in Lake Hummeln, 150 miles southwest of Stockholm, was caused by the impact of a meteorite some 600 million years ago (Svensson, N. B., Sver. Geol. Unders. Afh., 60, part 3, 1966). The crater, which is excavated in Pre-Cambrian granite, was probably exhumed by ice during the Ice Age. Evidence for a meteoritic origin is the presence of an uncon. solidated breccia composed of pieces of the granitic basement and the shape of the crater, which is flat bottomed with a pronounced rim. It is thought that shortly after the formation of the crater the area was covered with Pre-Cambrian sandstone, thus preserving a feature which, if it had been exposed to the elements, would have rapidly become unrecognizable. A vol- canic origin for the crater is improbable as no contemporary volcanic activity is known in the area, while a tectonic origin is ruled out on the grounds that the last demonstrable tectonism in the area was some 500 million years earlier than the formation of the crater. If the depression in the floor of Lake Hummeln is indeed an impact crater, then it is one of the earliest examples in the geological record.

\section{Sound of the Walrus}

THE sounds made underwater by Olaf, a ten year old Atlantic walrus (Odobenus rosmaris), have been recorded at the New York Aquarium. The sounds can be heard on a gramophone record which is included in the latest edition of Zoologica, published by the New York Zoological Society.

The underwater sounds are distinct from the bellow, grunt and mellow whistle made by the walrus in the air. Underwater, the walrus produces rasps, clicks and bell-like sounds, with mouth closed and head submerged. The rasps and clicks are of short duration, $0 \cdot 1-0 \cdot 2$ sec and $0 \cdot 015-0 \cdot 020$ sec respectively. The clicks are produced in rapid sequences and resemble quiet machine gun fire. The rasp is the type of noise which is produced by blowing through closed lips. Olaf, with a damaged eye, had no difficulty in swimming, even with eyes closed. The rasps and clicks which he emitted in the process could have been for echo-location; but, as the report points out, the walrus was in familiar surroundings and may have been relving on memory for his orientation.

The bell like sound lasts longer $(1-1.5 \mathrm{sec})$ than the rasps or clicks and is hollow and metallic, like the sound of distant cymbals. It is associated with the derelopment of the pharyngeal pouches, which can inflate to balloon like proportions on each side of the head of this animal and which help in floating. The walrus floats when it is sexually active, and it was on such occasions that the bell like sound was heard. Confirmation that the pharyngeal pouches act as resonators for this sound was also obtained at the death of a walrus with a pouch inflated, after a hunt by Eskimos; when the pouch was stripped of skin and fat and struck with the flat of a knife blade, a bell like sound almost identical with that recorded was heard.

\section{Dorcas Gazelles}

L. I. Ghobrial and J. L. Cloudsley-Thompson write from the Department of Zoology at the University of Khartoum about their recent note on the effect of water deprivation on the Dorcas gazelle (Nature, $212,306 ; 1966)$. "We are disturbed to learn that some readers thought that the death from drought of two experimental animals was caused deliberately. Humanitarian reasons apart, the loss of these valuable gazelles was a severe blow to our programme of research. We never expected that death would follow a percentage loss of body wejght so small compared with what the camel and the sheep can tolerate. As soon as our animals became weak and a big increase in blood urea was noted, they were given water and salt. Despite this, they died after about $12 \mathrm{~h}$. We are sorry if our purely factual statement has misled your readers." 